\title{
Early time course of major bleeding on antiplatelet therapy after TIA or ischemic stroke
}

Nina A. Hilkens, MD, Ale Algra, MD, PhD, L. Jaap Kappelle, MD, PhD, Philip M. Bath, FRCP, DSc, László Csiba, MD, PhD, Peter M. Rothwell, MD, PhD, FRCP, FMedSci, and Jacoba P. Greving, PhD On behalf of the CAT Collaboration

Neurology ${ }^{\circledR}$ 2018;90:e683-e689. doi:10.1212/WNL.0000000000004997

\section{Abstract}

\section{Objective}

To study the early time course of major bleeding and its subtypes in patients with cerebral ischemia on dual and single antiplatelet therapy.

\section{Methods}

We performed a post hoc analysis on individual patient data from 6 randomized clinical trials (Clopidogrel Versus Aspirin in Patients at Risk of Ischaemic Events [CAPRIE], Second European Stroke Prevention Study [ESPS-2], Management of Atherothrombosis With Clopidogrel in High-Risk Patients [MATCH], Clopidogrel for High Atherothrombotic Risk and Ischemic Stabilization, Management, and Avoidance [CHARISMA], European/Australasian Stroke Prevention in Reversible Ischaemia Trial [ESPRIT], and Prevention Regimen for Effectively Avoiding Second Strokes [PRoFESS]) including 45,195 patients with a TIA or noncardioembolic ischemic stroke. We studied incidence rates of bleeding per antiplatelet regimen stratified by time from randomization ( $\leq 30,31-90,91-180,181-365,>365$ days). We calculated incidence rates per trial and pooled estimates with random-effects meta-analysis. We performed Poisson regression to assess differences between time periods with adjustment for age and sex.

\section{Results}

The incidence of major bleeding on aspirin plus clopidogrel and aspirin plus -dipyridamole was highest in the first 30 days, 5.8 and 4.9 per 100 person-years, respectively, and was significantly higher than at 31 to 90 days (rate ratio 1.98, 95\% confidence interval 1.16-3.40 for aspirin plus clopidogrel; rate ratio 1.94, 95\% confidence interval 1.24-3.03 for aspirin plus dipyridamole). Incidence rates on aspirin and clopidogrel monotherapy were 2.8 and 2.5 per 100 person-years, respectively, in the first 30 days, with no significant change over time. The time course was similar for gastrointestinal bleeds. There was no early excess of intracranial hemorrhage in patients on either dual or single antiplatelet therapy.

\section{Conclusion}

Dual antiplatelet therapy is associated with high early risks of major and gastrointestinal bleeding that decline after the first month in trial cohorts.

\author{
Correspondence \\ Dr. Hilkens \\ n.a.hilkens-3@ \\ umcutrecht.nl
}




\section{Glossary}

CAPRIE $=$ Clopidogrel Versus Aspirin in Patients at Risk of Ischaemic Events; CHANCE $=$ Clopidogrel in High-Risk Patients With Acute Nondisabling Cerebrovascular Events; CHARISMA = Clopidogrel for High Atherothrombotic Risk and Ischemic Stabilization, Management, and Avoidance; CI = confidence interval; ESPRIT = European/Australasian Stroke Prevention in Reversible Ischaemia Trial; ESPS-2 = Second European Stroke Prevention Study; EXPRESS = Effect of Urgent Treatment of Transient Ischemic Attack and Minor Stroke on early Recurrent Stroke; FASTER = Fast Assessment of Stroke and Transient Ischaemic Attack to Prevent Early Recurrence; MATCH = Management of Atherothrombosis With Clopidogrel in High-Risk Patients; PRoFESS = Prevention Regimen for Effectively Avoiding Second Strokes; RR = rate ratio; SPS3 = Secondary Prevention of Small Subcortical Strokes Trial; TARDIS = Triple Antiplatelets for Reducing Dependency in Ischaemic Stroke.

Antiplatelet drugs are widely applied in the secondary prevention of cardiovascular disease. Although they successfully reduce the risk of recurrent ischemic events, ${ }^{1}$ antiplatelet drugs are associated with a small but relevant risk of serious bleeding, ${ }^{1}$ which is reported to vary between $1 \% / y$ and $1.5 \% /$ $\mathrm{y}^{2,3}$ The prognosis of patients who have experienced a bleeding event is worse, with higher all-cause and cardiovascular mortality. ${ }^{4}$ Given the wide application of antiplatelet therapy and consequences of bleeding events, it is important to gain more insight into the safety of antiplatelet agents.

It has been shown previously that the excess risk of major bleeding on aspirin compared with placebo falls with time in primary prevention trials, driven mainly by an excess early risk of bleeding on aspirin. ${ }^{5}$ It is uncertain whether the time course would be the same in the secondary prevention of cerebral ischemia. In addition, it is unknown whether the time course differs for dual antiplatelet therapy, which is known to be associated with higher risks of bleeding than monotherapy. ${ }^{6,7}$ Indeed, there is some preliminary evidence of a high early risk of bleeding on dual antiplatelet treatment after TIA and minor stroke, particularly among aspirin-naive patients, ${ }^{8}$ but larger studies are required. We aimed to study the time course of major bleeding events and their subtypes in patients with cerebral ischemia on dual and single antiplatelet therapy.

\section{Methods}

\section{Study population}

We analyzed individual patient data from 6 randomized clinical trials (Clopidogrel Versus Aspirin in Patients at Risk of Ischaemic Events [CAPRIE], Second European Stroke Prevention Study [ESPS-2], Management of Atherothrombosis With Clopidogrel in High-Risk Patients [MATCH], Clopidogrel for High Atherothrombotic Risk and Ischemic Stabilization, Management, and Avoidance [CHARISMA], European/Australasian Stroke Prevention in Reversible Ischaemia Trial [ESPRIT], and Prevention Regimen for Effectively Avoiding Second Strokes [PRoFESS] $]^{6,7,9-12}$ ) investigating the efficacy of antiplatelet agents in patients with a TIA or ischemic stroke. Details of the individual patient data meta-analysis have been described previously. ${ }^{13}$ In total, 48,023 patients with cerebral ischemia were included in the trials between 1989 and 2006. Details of the included trials are presented in table 1 . Aspirin was studied in 4 trials (CAPRIE, ESPS-2, CHARISMA, and ESPRIT), clopidogrel was studied in 3 (CAPRIE, MATCH, and PRoFESS), aspirin in combination with (extended-release) dipyridamole was examined in 3 (ESPS-2, ESPRIT, and PRoFESS), and aspirin in combination with clopidogrel was assessed in 2 (MATCH and CHARISMA). The ESPS- 2 trial had 4 arms and randomized patients to aspirin, aspirin plus extended-release dipyridamole, extended-release dipyridamole only, or placebo. Median follow-up ranged from 1.4 to 3.5 years.

We excluded patients with a possible cardioembolic origin of their stroke (those with a history of atrial fibrillation or Trial of ORG 10172 in Acute Stroke Treatment classification of cardioembolic stroke). We used trial-specific definitions for major bleeding. Major bleeding events included bleedings that were fatal, intracranial, or significantly disabling or required hospital admission. Intracranial bleeding events included intracerebral hemorrhages, subarachnoid hemorrhages, and subdural and epidural hematomas. Hemorrhagic transformations of ischemic strokes were not counted as intracranial hemorrhages. Gastrointestinal bleeding events included upper and lower gastrointestinal bleeds that were fatal or required hospital admission.

\section{Statistical analysis}

We restricted our analyses to patients who were on treatment. For patients who permanently discontinued trial medication, on-treatment time was defined as time until last intake of study drugs plus 28 days. For patients who completed the trial, on-treatment time was the same as intention-to-treat time. We calculated incidence rates of bleeding per antiplatelet regimen stratified by time from randomization $(\leq 30,31-90,91-180,181-365$, and $>365$ days). Incidence rates were calculated for each trial separately and were subsequently pooled per antiplatelet regimen with random-effects meta-analysis. We performed Poisson regression analysis to quantify the difference between time periods with adjustment for age and sex. Rate ratios were calculated per trial and subsequently pooled per antiplatelet regimen with random-effects meta-analysis. The time period of 31 to 90 days was chosen as the reference category in all analyses. We examined the influence of age 
Table 1 Overview of included trials

\begin{tabular}{|c|c|c|c|c|c|c|c|}
\hline Trial, year & $\begin{array}{l}\text { Recruitment } \\
\text { period }\end{array}$ & No. & Intervention & $\begin{array}{l}\text { Time to } \\
\text { randomization, } \\
\text { median (IQR), d }\end{array}$ & Inclusion criteria & $\begin{array}{l}\text { Mean } \\
\text { age } \\
\text { (SD), y }\end{array}$ & $\begin{array}{l}\text { Follow-up, } \\
\text { median } \\
\text { (range), y }\end{array}$ \\
\hline $\begin{array}{l}\text { CAPRIE, stroke } \\
\text { subgroup, } 1996\end{array}$ & 1992-1995 & 6,431 & C vs A & $34(16-80)$ & IS within 6 mo & $65(11.1)$ & $2.0(0-3.3)$ \\
\hline ESPS-2, 1996 & 1989-1993 & 6,602 & $\begin{array}{l}A+D \text { vs } A \text { vs } D \\
\text { vs placebo }\end{array}$ & $22(9-48)$ & TIA/IS within 3 mo & $67(11.1)$ & $2.0(0-5.7)$ \\
\hline МАTCH, 2004 & $2000-2002$ & 7,599 & $A+C$ vs $C$ & $15(8-39)$ & $\begin{array}{l}\text { TIA/IS within } 3 \text { mo and } 1 \\
\text { additional vascular risk factor } \\
\text { within } 3 y\end{array}$ & $66(9.9)$ & $1.5(0-1.5)$ \\
\hline $\begin{array}{l}\text { CHARISMA, } \\
\text { stroke } \\
\text { subgroup, } 2006\end{array}$ & 2002-2003 & 4,320 & $A+C$ vs $A$ & $126(19-510)$ & TIA/IS within 5 y; age $\geq 45 y$ & $65(9.8)$ & $2.1(0-2.9)$ \\
\hline ESPRIT, 2006 & 1997-2005 & 2,739 & $A+D$ vs $A$ & $50(21-84)$ & TIA/minor IS within 6 mo & $63(10.9)$ & $3.4(0-8.1)$ \\
\hline PRoFESS, 2008 & $2003-2006$ & 20,332 & $A+D$ vs $C$ & $15(7-39)$ & $\begin{array}{l}\text { IS within } 3 \text { mo; clinically and } \\
\text { neurologically stable; age } \geq 55 \text { y }\end{array}$ & $66(8.6)$ & $2.4(0-4.4)$ \\
\hline
\end{tabular}

Abbreviations: $\mathrm{A}$ = aspirin; $\mathrm{C}=$ clopidogrel; CAPRIE = Clopidogrel Versus Aspirin in Patients at Risk of Ischaemic Events; CHARISMA = Clopidogrel for High Atherothrombotic Risk and Ischemic Stabilization, Management, and Avoidance; D = dipyridamole; ESPRIT = European/Australasian Stroke Prevention in Reversible Ischaemia Trial; ESPS-2 = Second European Stroke PreventionStudy; IQR = interquartile range; IS = ischemic stroke; MATCH = Management of Atherothrombosis With Clopidogrel in High-Risk Patients With Recent TIA or Ischaemic Stroke.

and prior antiplatelet drug use on the time course of bleeding by performing stratified analyses. Definitions of prior antiplatelet drug use varied considerably across trials; therefore, we used prior vascular disease as a proxy for longterm prior antiplatelet drug use, which we defined as a medical history of stroke, TIA, myocardial infarction, angina, or peripheral artery disease. All analyses were performed with $\mathrm{R}$ version 3.2.2.

\section{Standard protocol approvals, registrations, and patients consents}

The trials were approved by the ethics committee or institutional review board at each participating center, and all patients gave written informed consent.

\section{Results}

After the exclusion of patients with a possible cardioembolic stroke $(\mathrm{n}=1,829)$ and patients who permanently discontinued treatment but for whom the date of last intake was unknown ( $\mathrm{n}=999$; rate of major bleeding 0.8 per 100 personyears), 45,195 patients remained for the analysis. During 82,199 person-years of follow-up, 1,338 major bleedings, 324 intracranial bleedings, and 618 gastrointestinal bleedings occurred. Baseline characteristics of patients are presented in table 2.

The time course of major bleeding per antiplatelet regimen is displayed in figure 1. The risk of major bleeding was highest during the first 30 days for all antiplatelet regimens except for dipyridamole only. The incidence rate was 2.8 per 100 person-years for aspirin, 2.5 per 100 person-years for clopidogrel, 4.9 per 100 person-years for aspirin plus dipyridamole, and 5.8 per 100 person-years for aspirin plus clopidogrel (figure e-1, http://links.lww.com/WNL/A167). Results per trial are shown in figures e-2 through e-6. In

Table 2 Baseline characteristics of 45,195 patients included in the analyses

\begin{tabular}{ll}
\hline & No. (\%) \\
\hline Mean age (SD), y & $65.5(9.8)$ \\
\hline Male sex & $28,595(63)$ \\
\hline Qualifying event & \\
\hline TIA & $5,013(11)$ \\
\hline Ischemic stroke & $40,179(89)$ \\
\hline Current smoking & $10,116(22)$ \\
\hline Hypertension & $33,325(74)$ \\
\hline Diabetes mellitus & $14,579(32)$ \\
\hline Prior stroke & $7,375(17)$ \\
\hline Prior myocardial infarction & $3,341(7)$ \\
\hline Prior vascular disease & $17,909(40)$
\end{tabular}

Type of antiplatelet

\begin{tabular}{lc}
\hline Aspirin & $8,103(18)$ \\
\hline Clopidogrel & $16,084(36)$ \\
\hline Aspirin + dipyridamole & $12,218(27)$ \\
\hline Aspirin + clopidogrel & $5,754(13)$ \\
\hline Dipyridamole & $1,521(3)$ \\
\hline Placebo & $1,515(3)$ \\
\hline
\end{tabular}




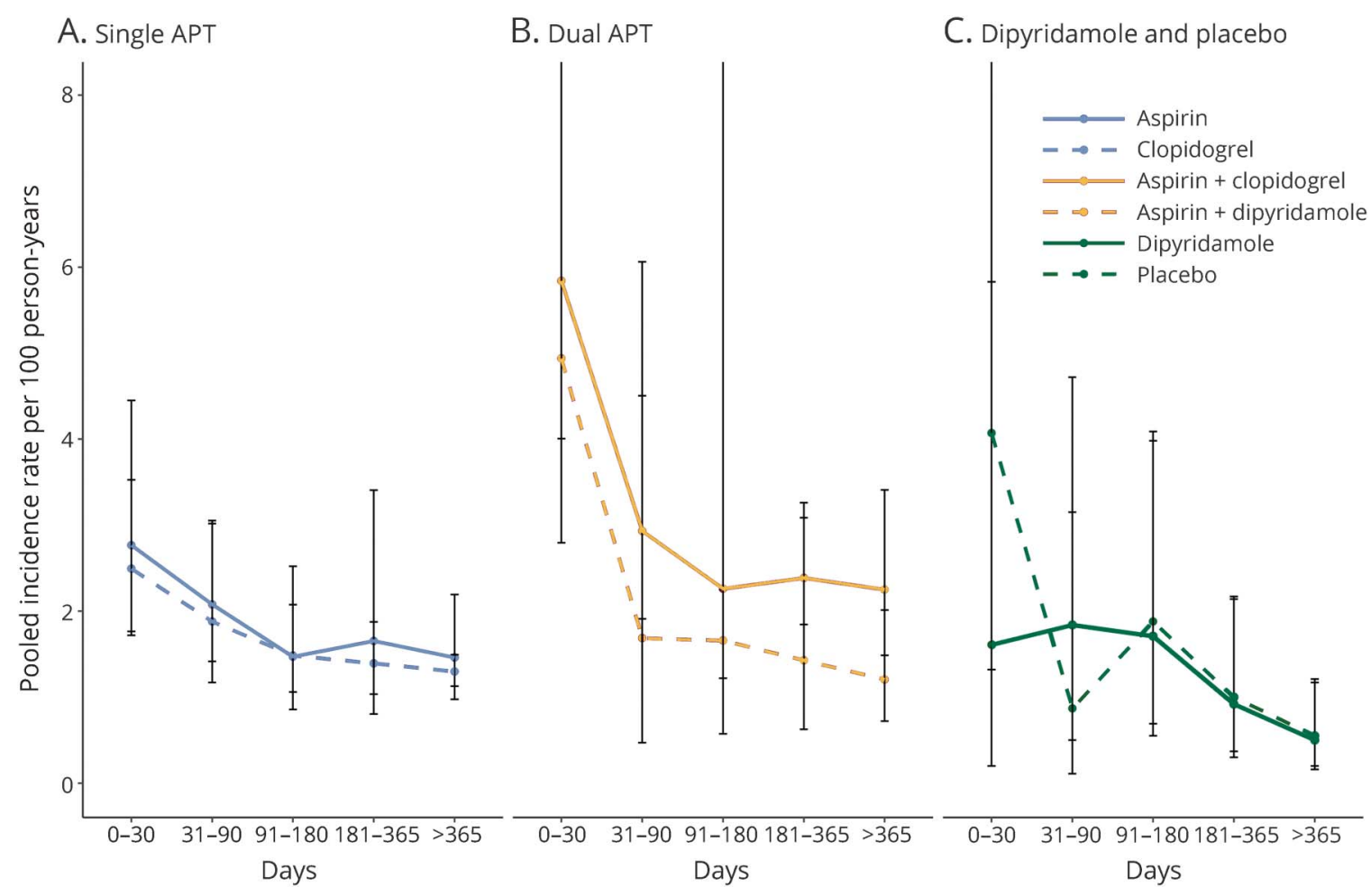

(A) Single antiplatelet therapy (APT), (B) dual APT, and (C) dipyridamole and placebo.

patients on dual antiplatelet therapy, the risk of major bleeding was significantly higher in the first 30 days compared with 31 to 90 days (rate ratio [RR] 1.98, 95\% confidence interval [CI] 1.16-3.40 for aspirin plus clopidogrel; RR 1.94, 95\% CI 1.24-3.03 for aspirin plus dipyridamole, table 3). No significant change over time was seen for single antiplatelet regimens (RR 1.27, 95\% CI 0.69-2.37 for aspirin; RR 1.28, 95\% CI 0.66-2.48 for clopidogrel; and RR $0.87,95 \%$ CI $0.12-4.44$ for dipyridamole, table 3 ). The same patterns were seen for gastrointestinal bleeds (figure 2A). Risk of intracranial hemorrhage was stable over time (figure 2B and table e-1, http://links.lww.com/WNL/A168).
Pooled incidence rates of gastrointestinal and intracranial bleeding per antiplatelet regimen are presented in figures e-7 and e-8.

Among elderly patients (age $\geq 65$ years), absolute risks of major bleeding were higher. The time course of the risk of bleeding was comparable for younger and older patients (figure e-9, http://links.lww.com/WNL/A167). A total of 17,909 patients $(40 \%)$ had a diagnosis of vascular disease before their presenting event. Patterns of bleeding risk over time were essentially similar for patients with and without prior vascular disease (figure e-10).

Table 3 Adjusted rate ratios (95\% confidence interval) for major bleeding

\begin{tabular}{llllll}
\hline & $\mathbf{0 - 3 0 ~ d}$ & $\mathbf{3 1 - 9 0 ~ d ~}$ & $\mathbf{9 1 - 1 8 0 ~ d ~}$ & $\mathbf{1 8 1 - 3 6 5 ~ d ~}$ & $\mathbf{> 3 6 5 ~ d}$ \\
\hline Aspirin & $1.27(0.69-2.37)$ & 1 (Referent) & $0.74(0.40-1.34)$ & $0.84(0.44-1.61)$ & $0.82(0.54-1.27)$ \\
\hline Clopidogrel & $1.28(0.66-2.48)$ & 1 (Referent) & $0.82(0.55-1.21)$ & $0.77(0.44-1.36)$ & $0.74(0.42-1.29)$ \\
\hline Aspirin + dipyridamole & $1.94(1.24-3.03)$ & 1 (Referent) & $0.66(0.42-1.03)$ & $0.62(0.42-0.91)$ & $0.62(0.44-0.87)$ \\
\hline Aspirin + clopidogrel & $1.98(1.16-3.40)$ & 1 (Referent) & $0.92(0.39-2.18)$ & $0.84(0.53-1.34)$ & $0.84(0.53-1.33)$ \\
\hline Dipyridamole & $0.87(0.12-4.44)$ & 1 (Referent) & $0.93(0.25-3.76)$ & $0.52(0.14-2.08)$ & $0.28(0.07-1.14)$ \\
\hline Placebo & $4.59(0.99-32.1)$ & 1 (Referent) & $2.16(0.50-14.8)$ & $1.19(0.27-8.10)$ & $0.66(0.15-4.50)$ \\
\hline
\end{tabular}

Adjusted for age and sex. 
Figure 2 Time course of $(A)$ gastrointestinal bleeding and(B) intracranial bleeding per antiplatelet regimen (pooled estimates)

\section{A. Gastrointestinal bleeding}

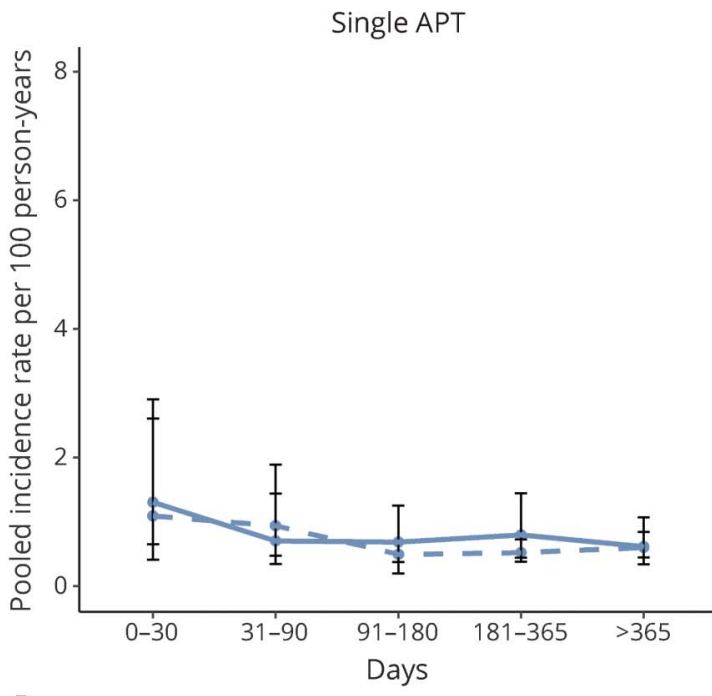

B. Intracranial bleeding

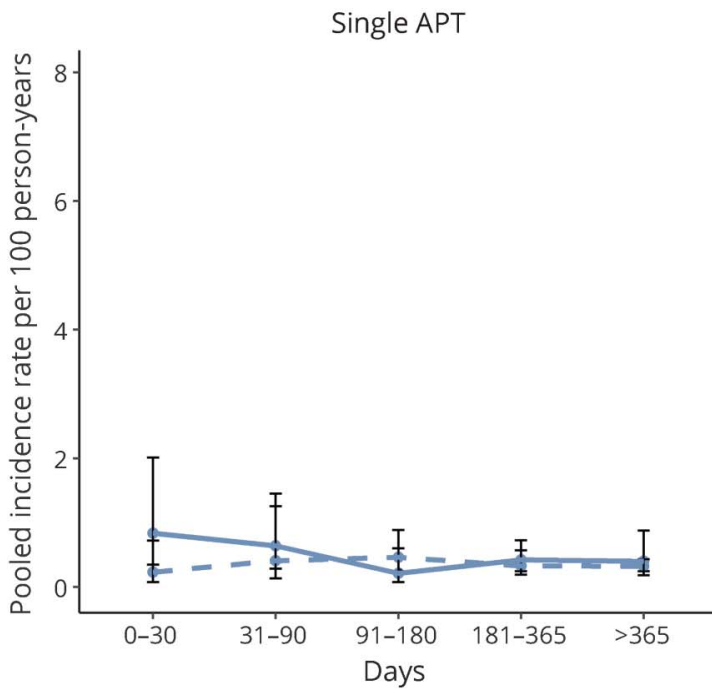

Dual APT

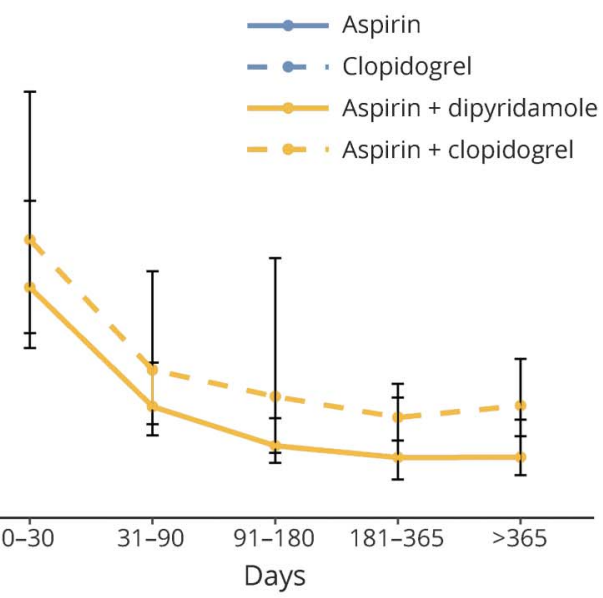

Dual APT

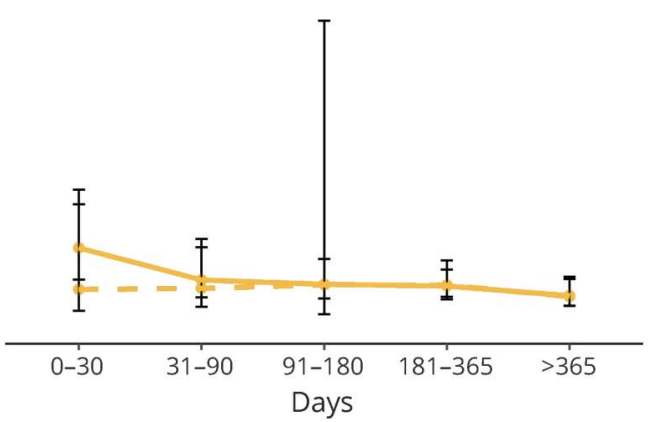

APT = antiplatelet therapy.

\section{Discussion}

Our study showed high early risks of major bleeding and, more specifically, gastrointestinal bleeding on dual antiplatelet therapy that decline over time. There was no early excess risk of intracranial hemorrhages among patients on either dual antiplatelet therapy or monotherapy.

Multiple trials have shown the increased risk of major bleeding associated with long-term dual antiplatelet therapy after stroke: MATCH, CHARISMA, and Secondary Prevention of Small Subcortical Strokes Trial (SPS3) demonstrated that aspirin plus clopidogrel is associated with statistically significant higher bleeding risks than either of the regimens separately. ${ }^{6,714}$ Furthermore, the PRoFESS trial showed that aspirin plus dipyridamole led to more major and intracranial bleedings than clopidogrel monotherapy. ${ }^{12}$ Recent trials have investigated the benefit of a short course of aspirin plus clopidogrel, aiming to reduce the risk of early recurrent strokes without exposing patients to long-term dual antiplatelet treatment. Combination therapy was shown to be more protective against ischemic events than monotherapy, but results regarding risk of bleeding in the early phase were conflicting. ${ }^{15,16}$ While the Clopidogrel in High-Risk Patients With Acute Nondisabling Cerebrovascular Events (CHANCE) trial showed similar risks of bleeding among both groups, ${ }^{15}$ the Fast Assessment of Stroke and Transient Ischaemic Attack to Prevent Early Recurrence (FASTER) 
trial showed a significantly higher risk of symptomatic and asymptomatic bleeds among patients treated with dual antiplatelet therapy. ${ }^{16}$ The recent Triple Antiplatelets for Reducing Dependency in Ischaemic Stroke (TARDIS) trial compared short-term triple therapy (aspirin plus dipyridamole plus clopidogrel) with guideline-based therapy and found no net clinical benefit due to an excess of bleeding complications with triple antiplatelet therapy. ${ }^{17}$

Evidence for a time course of bleeding risk is scarce. Post hoc analyses on data from CHARISMA showed that the excess risk of bleeding on aspirin plus clopidogrel was greatest in the first year and similar to aspirin thereafter. ${ }^{18,19}$ This is in line with our results indicating high early risks on dual antiplatelet therapy that decline over time. Results from this study and ours suggest that some form of resistance to antiplatelet drugs occurs over time. Previous studies investigating platelet response over time have shown conflicting results. Some reported stable platelet reactivity, ${ }^{20}$ while others showed decreased platelet inhibition after the first months of exposure to both aspirin and clopidogrel. ${ }^{21-23}$ The mechanisms that cause this reduced sensitivity over time remain unclear. Possibly, upregulation of other pathways that mediate platelet aggregation may play a role. Our findings may also suggest that patients who are prone to bleeding experience a bleed shortly after the start of treatment, leaving a cohort that is at relatively lower risk. Alternatively, the high early risk may be explained partly by the natural history of bleeds as suggested by the time course in placebo-treated patients. However, the number of bleeds in the placebo group was small, and analyses of other data sources are required to better understand the natural history of bleeding after stroke.

High bleeding risks on aspirin plus clopidogrel have been reported previously and are a cause for concern. A post hoc analysis on data from the Effect of Urgent Treatment of Transient Ischemic Attack and Minor Stroke on early Recurrent Stroke (EXPRESS) study and FASTER pilot trial showed excessive risks during the first 90 days, particularly among aspirin-naive patients. ${ }^{8}$ Whether the risk decreased over time was not investigated. The high observed risks were attributed partly to the fact that patients were vulnerable shortly after their TIA or ischemic stroke. However, our data show that after the acute phase of TIA or stroke, initiation of dual antiplatelet therapy is accompanied by a doubling of risk in the first 30 days.

Our study addresses the time course of gastrointestinal and intracranial bleeding separately. The finding that aggressive antiplatelet therapy has a more pronounced effect on gastrointestinal bleeding is plausible because patients with inherited and acquired platelet disorders often present with mucocutaneous bleeding patterns. ${ }^{24}$

A strength of our study is the large sample size with a large number of bleeding events. In addition, the quality of the data was high, with regular follow-up and adjudication of events by an independent committee. Furthermore, we were able to restrict our analysis to patients who were on treatment, thereby reducing the possibility that our findings reflect poor compliance. Our study also has limitations. First, we did not have data on other antiplatelet agents such as cilostazol, terutroban, or triflusal. However, the antiplatelet drugs investigated in our study are those recommended as first-line agents in current guidelines. ${ }^{25,26}$ Second, absolute risks of bleeding may have been underestimated because patients at highest bleeding risk were excluded from the trials. It is also possible that the time course of bleeding risk might differ in older or frailer populations. Third, control of medication intake was not performed in all trials; therefore, we cannot exclude that patients who were included in the on-treatment analyses in reality did not take their medication anymore. Finally, we performed a post hoc analysis on trial data, and although adjustment for age and sex did not change the results, the possibility of residual confounding remains.

The risk of major bleeding and, more specifically, gastrointestinal bleeding is increased 2-fold in the first month on dual antiplatelet treatment. The risk of intracranial hemorrhage is stable over time. Although the risk of early recurrent ischemic events will likely outweigh the risk of bleeding, our findings draw attention to the high early risks of bleeding associated with dual antiplatelet therapy, which may have previously been underestimated. The high early risks may warrant the initiation of gastroprotective agents in patients on dual antiplatelet therapy, as well as close monitoring of patients in the early phase.

\section{Author contributions}

N.A.H. did the statistical analysis, wrote the first draft of the article, and was supervised by J.P.G., N.A.H., A.A., L.J.K., P.M.R, and J.P.G. made substantial contributions to the conception and design of the study, data analysis, and in terpretation of data; they also contributed to drafting of the article and its critical revision for important intellectual content. P.M.B. and L.C. were involved in data collection, interpretation of the data, and revision of the manuscript for important intellectual content. J.P.G. had the final responsibility for the analyses and the content of the article.

\section{Acknowledgment}

The authors thank the ESPRIT Steering Committee for providing access to the ESPRIT data and Sanofi-Aventis and Bristol-Myers Squibb for giving access to the databases of CAPRIE, MATCH, and CHARISMA. Boehringer Ingelheim Pharmaceuticals, Inc supported this work by providing access to the clinical trial databases of ESPS- 2 and PRoFESS.

\section{Study funding}

Dr. J.P. Greving and Dr N.A. Hilkens are supported by a grant from the Dutch Heart Foundation (grant 2013T128). Dr. Greving is also supported by a VENI grant from the Netherlands Organization for Health Research and Development (ZonMw), grant 916.11.129. 


\section{Disclosure}

The authors report no disclosures relevant to the manuscript. Go to Neurology.org/N for full disclosures.

Received July 7, 2017. Accepted in final form November 14, 2017.

\section{References}

1. Antithrombotic Trialists' (ATT) Collaboration, Baigent C, Blackwell L, et al. Aspirin in the primary and secondary prevention of vascular disease: collaborative metaanalysis of individual participant data from randomised trials. Lancet 2009;373: 1849-1860.

2. Li L, Geraghty OC, Mehta Z, Rothwell PM; Oxford Vascular Study. Age-specific risks, severity, time course, and outcome of bleeding on long-term antiplatelet treatment after vascular events: a population-based cohort study. Lancet 2017;390:490-499.

3. Alberts MJ, Bhatt DL, Smith SC Jr, et al. Risk factors and outcomes for patients with vascular disease and serious bleeding events. Heart 2011;97:1507-1512.

4. Berger JS, Bhatt DL, Steg PG, et al. Bleeding, mortality, and antiplatelet therapy: results from the Clopidogrel for High Atherothrombotic Risk and Ischemic Stabilization, Management, and Avoidance (CHARISMA) trial. Am Heart J 2011;162: 98-105.e1.

5. Rothwell PM, Price JF, Fowkes FG, et al. Short-term effects of daily aspirin on cancer incidence, mortality, and non-vascular death: analysis of the time course of risks and benefits in 51 randomised controlled trials. Lancet 2012;379:1602-1612.

6. Bhatt DL, Fox KA, Hacke W, et al. Clopidogrel and aspirin versus aspirin alone for the prevention of atherothrombotic events. N Engl J Med 2006;354:1706-1717.

7. Diener HC, Bogousslavsky J, Brass LM, et al. Aspirin and clopidogrel compared with clopidogrel alone after recent ischaemic stroke or transient ischaemic attack in highrisk patients (MATCH): randomised, double-blind, placebo-controlled trial. Lancet 2004;364:331-337.

8. Geraghty OC, Kennedy J, Chandratheva A, Marquardt L, Buchan AM, Rothwell PM. Preliminary evidence of a high risk of bleeding on aspirin plus clopidogrel in aspirinnaive patients in the acute phase after TIA or minor ischaemic stroke. Cerebrovasc Dis 2010;29:460-467.

9. CAPRIE Steering Committee. A randomised, blinded, trial of clopidogrel versus aspirin in patients at risk of ischaemic events (CAPRIE): CAPRIE Steering Committee. Lancet 1996;348:1329-1339.

10. Diener HC, Cunha L, Forbes C, Sivenius J, Smets P, Lowenthal A. European Stroke Prevention Study 2: dipyridamole and acetylsalicylic acid in the secondary prevention of stroke. J Neurol Sci 1996;143:1-13.

11. ESPRIT Study Group, Halkes PH, van Gijn J, Kappelle LJ, Koudstaal PJ, Algra A. Aspirin plus dipyridamole versus aspirin alone after cerebral ischaemia of arterial origin (ESPRIT): randomised controlled trial. Lancet 2006;367:1665-1673.
12. Sacco RL, Diener HC, Yusuf S, et al. Aspirin and extended-release dipyridamole versus clopidogrel for recurrent stroke. N Engl J Med 2008;359:1238-1251.

13. Greving JP, Diener HC, Csiba L, et al. Individual patient data meta-analysis of antiplatelet regimens after noncardioembolic stroke or TIA: rationale and design. Int J Stroke 2015;10(suppl A100):145-150.

14. SPS3 Investigators, Benavente OR, Hart RG, et al. Effects of clopidogrel added to aspirin in patients with recent lacunar stroke. N Engl J Med 2012;367:817-825.

15. Wang Y, Wang Y, Zhao X, et al. Clopidogrel with aspirin in acute minor stroke or transient ischemic attack. N Engl J Med 2013;369:11-19.

16. Kennedy J, Hill MD, Ryckborst KJ, et al. Fast Assessment of Stroke and Transient Ischaemic Attack to Prevent Early Recurrence (FASTER): a randomised controlled pilot trial. Lancet Neurol 2007;6:961-969.

17. Bath PM, Woodhouse LJ, Flaherty K, Havard D, England TJ, Sprigg N. Intensive versus guideline antiplatelet therapy for preventing recurrence in patients with acute ischaemic stroke or TIA: main results from the Triple Antiplatelets for Reducing Dependency in Ischaemic Stroke (TARDIS) Trial. Presented at the 2017 International Stroke Conference; February 22-24, 2017; Houston, TX.

18. Berger PB, Bhatt DL, Fuster V, et al. Bleeding complications with dual antiplatelet therapy among patients with stable vascular disease or risk factors for vascular disease: results from the Clopidogrel for High Atherothrombotic Risk and Ischemic Stabilization, Management, and Avoidance (CHARISMA) trial. Circulation 2010;121: 2575-2583.

19. Bhatt DL, Flather MD, Hacke W, et al. Patients with prior myocardial infarction, stroke, or symptomatic peripheral arterial disease in the CHARISMA trial. J Am Coll Cardiol 2007;49:1982-1988.

20. Saw J, Madsen EH, Chan S, Maurer-Spurej E. The ELAPSE (Evaluation of LongTerm Clopidogrel Antiplatelet and Systemic Anti-Inflammatory Effects) study. J Am Coll Cardiol 2008;52:1826-1833.

21. Helgason CM, Bolin KM, Hoff JA, et al. Development of aspirin resistance in persons with previous ischemic stroke. Stroke 1994;25:2331-2336.

22. Nuhrenberg TG, Stratz C, Leggewie S, et al. Temporal variability in the antiplatelet effects of clopidogrel and aspirin after elective drug-eluting stent implantation: an ADAPT-DES substudy. Thromb Haemost 2015;114:1020-1027.

23. Pulcinelli FM, Pignatelli P, Celestini A, Riondino S, Gazzaniga PP, Violi F. Inhibition of platelet aggregation by aspirin progressively decreases in long-term treated patients. J Am Coll Cardiol 2004;43:979-984.

24. Hassan AA, Kroll MH. Acquired disorders of platelet function. Hematology Am Soc Hematol Educ Program 2005:403-408.

25. Kernan WN, Ovbiagele B, Black HR, et al. Guidelines for the prevention of stroke in patients with stroke and transient ischemic attack: a guideline for healthcare professionals from the American Heart Association/American Stroke Association. Stroke 2014;45:2160-2236.

26. European Stroke Organisation (ESO) Executive Committee, ESO Writing Committee. Guidelines for management of ischaemic stroke and transient ischaemic attack 2008. Cerebrovasc Dis 2008;25:457-507. 


\section{Early time course of major bleeding on antiplatelet therapy after TIA or ischemic stroke}

Nina A. Hilkens, MD, Ale Algra, MD, PhD, L. Jaap Kappelle, MD, PhD, Philip M. Bath, FRCP, DSc, László Csiba, MD, PhD, Peter M. Rothwell, MD, PhD, FRCP, FMedSci, and Jacoba P. Greving, PhD On behalf of the CAT Collaboration

Cite as: Neurology ${ }^{\circledR}$ 2018;90:e683-e689. doi:10.1212/WNL.0000000000004997

\author{
Correspondence \\ Dr. Hilkens \\ n.a.hilkens-3@ \\ umcutrecht.nl
}

\section{Study question}

Does the early time course of major bleeding events in patients with cerebral ischemia differ between those prescribed dual antiplatelet therapy and those prescribed single antiplatelet therapy?

\section{Summary answer}

Dual antiplatelet therapy is associated with a high risk of major bleeding that declines after the first month. The risk of major bleeding on single antiplatelet therapy does not change over time.

\section{What is known and what this paper adds}

Antiplatelet therapy after ischemic stroke is associated with a small increase in the risk of major bleeding, and dual antiplatelet therapy aggravates this risk. Preliminary evidence suggests that risk of bleeding on dual therapy may be particularly high early after the start of treatment. This study provides evidence from a large cohort that confirms the greater risk of dual antiplatelet therapy early after initiation.

\section{Participants and setting}

This study analyzed data from 45,195 patients with a TIA or noncardioembolic ischemic stroke who participated in any of 6 RCTs conducted between 1989 and 2006 that examined the efficacies of different antiplatelet therapies.

\section{Design, size, and duration}

The study retrospectively meta-analyzed data from the 6 RCTs to determine how drug exposures affected outcomes. Of the patients, $8,103(18 \%)$ received aspirin alone, $16,084(36 \%)$ received clopidogrel alone, 1,521 (3\%) received dipyridamole alone, 12,218 (27\%) received aspirin-dipyridamole therapy, 5,754 (13\%) received aspirinclopidogrel therapy, and 1,515 (3\%) received placebo treatments.

\section{Primary outcomes}

The primary outcome was a major bleeding event, which was defined as being fatal, intracranial, or substantially disabling or necessitating hospitalization.

\section{Main results and the role of chance}

During 82,199 person-years of follow-up, there were 1,338 major bleeding events. Incidence rates within the first 30 days were higher for aspirin-dipyridamole therapy (4.9 per 100 personyears) and aspirin-clopidogrel therapy (5.8 per 100 person-years) than for aspirin alone (2.8 per 100 person-years) or clopidogrel

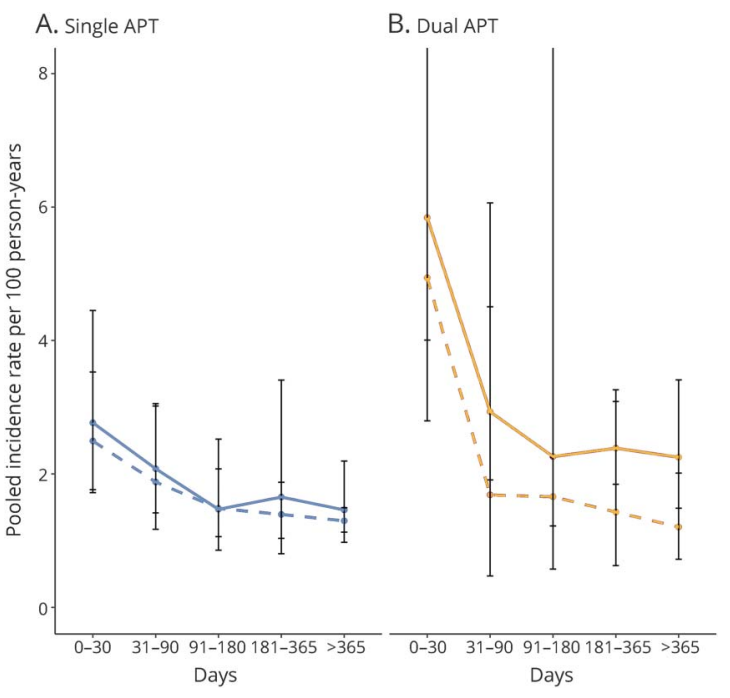

alone ( 2.5 per 100 person-years). Incidence rates within the first 30 days were greater than those over the next 60 days for dual antiplatelet therapy but not for single antiplatelet therapy after adjustment for age and sex (figure).

Bias, confounding, and other reasons for caution The study is a post hoc analysis of clinical trials. The RCTs did not all thoroughly control medication intake.

\section{Generalizability to other populations}

The study may have underestimated bleeding risks because the trials excluded patients at the highest risk of bleeding. The time course of bleeding might differ in older or frailer populations.

\section{Study funding/potential competing interests}

This work was funded by the Dutch Heart Foundation and the Netherlands Organization for Health Research and Development. Sanofi-Aventis, Bristol-Myers Squibb, Boehringer Ingelheim, and the European/Australasian Stroke Prevention in Reversible Ischaemia Trial (ESPRIT) Steering Committee provided access to randomized controlled trial (RCT) data. Go to Neurology.org/ $\mathrm{N}$ for full disclosures. 


\section{Neurology}

\section{Early time course of major bleeding on antiplatelet therapy after TIA or ischemic stroke}

Nina A. Hilkens, Ale Algra, L. Jaap Kappelle, et al.

Neurology 2018;90;e683-e689 Published Online before print January 26, 2018

DOI 10.1212/WNL.0000000000004997

This information is current as of January 26, 2018

Updated Information \& Services

References

Citations

Subspecialty Collections

Permissions \& Licensing

Reprints including high resolution figures, can be found at: http://n.neurology.org/content/90/8/e683.full

This article cites 24 articles, 7 of which you can access for free at: http://n.neurology.org/content/90/8/e683.full\#ref-list-1

This article has been cited by 2 HighWire-hosted articles: http://n.neurology.org/content/90/8/e683.full\#\#otherarticles

This article, along with others on similar topics, appears in the following collection(s):

All Cerebrovascular disease/Stroke

http://n.neurology.org/cgi/collection/all_cerebrovascular_disease_strok e

Infarction

http://n.neurology.org/cgi/collection/infarction

Prognosis

http://n.neurology.org/cgi/collection/prognosis

Stroke prevention

http://n.neurology.org/cgi/collection/stroke_prevention

Information about reproducing this article in parts (figures,tables) or in its entirety can be found online at:

http://www.neurology.org/about/about_the_journal\#permissions

Information about ordering reprints can be found online:

http://n.neurology.org/subscribers/advertise

Neurology ${ }^{\circledR}$ is the official journal of the American Academy of Neurology. Published continuously since 1951, it is now a weekly with 48 issues per year. Copyright @ 2018 The Author(s). Published by Wolters Kluwer Health, Inc. on behalf of the American Academy of Neurology.. All rights reserved. Print ISSN: 0028-3878. Online ISSN: 1526-632X.

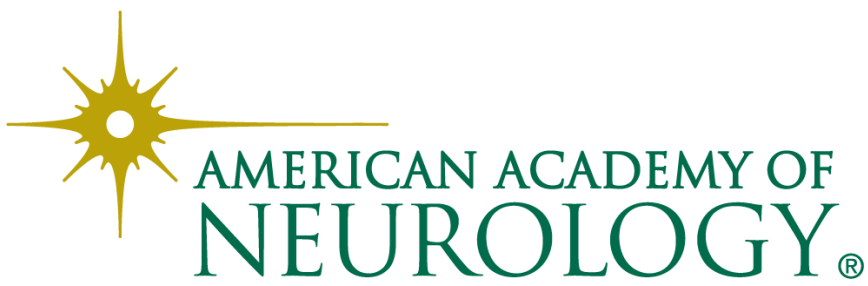

